\title{
Acute care for renal colic in Canadian healthcare - a commentary on emergency department patient flow metrics and treatment options
}

\author{
Zachary A. Valley, BSc; Kamaljot S. Kaler, MD, FRCSC
}

Department of Surgery, Section of Urology, University of Calgary, Calgary, AB, Canada

Cite as: Can Urol Assoc J 2020;14(8):265-6. hitp://dx.doi.org/10.5489/cuaj.6823

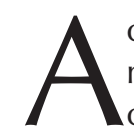
cute care surgery is a rapidly growing treatment modality for delivering emergency general surgical care throughout Canada and has been for some time. ${ }^{1}$ However, an acute care model within the field of urology is generally lacking, despite numerous studies analyzing surgical intervention for acute ureteral stones. ${ }^{2-5}$ In this issue of CUAJ, Kirubarajan et al describe the implementation an acute care urology (ACU) model at a large, communitybased hospital in Toronto, Canada. ${ }^{6}$ Briefly, the ACU model described included dedicated ACU daytime operating room (OR) blocks, a dedicated ACU surgeon, and a creation of a rapid referral clinic for emergency department (ED) patient referrals in 2016. Their study focused mainly on evaluating the impact of an ACU model on patient flow metrics, including ED length of stay, time from urology referral to consultation, and number of after-hours surgeries for treatment of renal colic. The researchers additionally determined patient and physician satisfaction using the ACU model. The study compared data of patients presenting to the ED with renal colic from pre- and post-ACU integration.

The study's results were favorable to the ACU model. The ED-to-clinic time was significantly lower for those in the ACU model, and there was a significantly greater rate of patients successfully receiving outpatient care. Fewer patients were lost to followup with the ACU model, and there was a significantly higher likelihood that patients would successfully obtain an outpatient urological appointment following referral. There was also a significant reduction in after-hours surgery in the ACU model compared to the control. Overall, the study illustrates that the ACU model results in more timely and reliable access to clinical, urological care for patients afflicted with an acute stone burden.

We applaud the authors on their results from the aforementioned study, and we wholeheartedly agree with the trend to integrate acute stone intervention into the ED. The "ACU model" has been in use for 20 years at the Rockyview General Hospital in Calgary, where a dedicated OR for urological intervention was implemented, as all urological care within the region is conducted at this hospital. This was indirectly analyzed in an unpublished study, conducted jointly between the University of Calgary and the University of British Columbia, where outcomes from early surgical intervention (intervention group) were compared to a trial of spontaneous passage (control group) for patients presenting to the ED with a diagnosis of renal colic. The intervention group consisted of patients who underwent immediate ureteroscopy in regard to the patient's ED presentation. The control group was defined as patients who had no intervention for more than five days or those who were discharged from their ED visit, failed conservative management, and returned to ED requiring rescue intervention. The study took place at four adult EDs within the Calgary Health Region and five adult EDs in the Vancouver Coastal Health Region.

The primary outcome variable of this study was treatment failure, which was defined as rescue intervention or hospitalization occurring between initial ED discharge and 60 days post-discharge. A total of 3081 patients were recruited and analyzed, with 1168 patients undergoing early surgical intervention and 1913 undergoing trial of spontaneous passage. For the patients who were offered spontaneous passage, treatment failure increased proportionally with stone width. It was determined that, for small stones $(<5 \mathrm{~mm})$, spontaneous passage was more effective and resulted in lower rates of procedure-related morbidity when compared to surgical intervention. However, it was found that morbidity related to early surgical intervention was diminished with large stones $(\geq 7 \mathrm{~mm}$ ) and had a greater success rate than spontaneous passage. Additionally, stone location was a strong predictor of treatment failure. Patients with proximal or mid-ureteral stones suffered more failure events than those with distal stones, regardless of stone size or management approach. Intermediate-sized (5-6 mm) stones in the distal ureter had similar outcomes with either management strategy, but intermediate-sized stones in the proximal or mid-ureter had more treatment failures with trial of spontaneous passage.

As such, we have refined our surgical model to include an "acute stone clinic" staffed solely by fellowship-trained endourologists, where patients with smaller stones can fol- 
low up in a timely manner (three weeks) to ensure passage. Accordingly, we have refined our guidelines for immediate intervention based on these data. However, stent management and related pain after surgery must not be forgotten and appropriate non-narcotic management must be initiated concurrently (such as alpha blockers, anti-cholinergics, and anti-inflammatories). We recommend a minimum of five days of an indwelling stent for distal stones and 7-10 days depending on ureteral access sheath use for proximal stones. We hope that the data from these studies may help current and future ACUs determine an optimized plan of care for patients presenting to the ED for renal colic and acute ureteral stones.

The emergence of ACU models, as described by Kirubarajan et al, is a modality that we believe would greatly improve the level of care for patients afflicted with acute ureteral stones, particularly in Canada. Case series from several countries have described stone-free rates of $90 \%$ after early intervention but with variable complication rates. ${ }^{3-5,7}$ With the implementation of the data presented in this study and our locally unpublished data, we hope that patients may be more appropriately selected for early surgical intervention, thus reducing morbidity associated with renal colic and time to surgery. We commend the efforts of Kirubarajan et al and intend to continue to define our ACU model, and hope it leads to widespread use of ACUs throughout Canada.
Competing interests: Dr. Kaler holds investments in Abbvie, Boston Scientific, Johnson \& Johnson, and Pfizer. Mr. Valley reports no competing personal or financial interests related to this work.

\section{References}

1. Hameed SM, Brenneman FD, Ball CG, et al. General surgery 2.0: The emergence of acute care surgery in Canada. Can I Surg 2010;53:79-83.

2. Zargar-Shoshtari K, Anderson W, Rice M. Role of emergency ureteroscopy in the management of ureteric stones: Analysis of 394 cases. BJU Int 2015;115:946-50. https://doi.org/10.1111/bju.12841

3. Picozzi SCM, Ricci C, Gaeta M, et al. Urgent ureteroscopy as first-line treatment for ureteral stones: A metaanalysis of 681 patients. Urol Res 2012;40:581-6. https://doi.org/10.1007/s00240-012-0469-z

4. Sarica $K$, Tanriverdi 0 , Aydin $M$, et al. Emergency ureteroscopic removal of ureteral calculi after first colic attack: Is there any advantage? Urology 2011;78:516-20. https://doi.org/10.1016/i.urology.2011.01.070

5. Al-Ghazo MA, Ghalayini IF, Al-Azab RS, et al. Emergency ureteroscopic lithotripsy in acute renal colic caused by ureteral calculi: A retrospective study. Urol Res 2011;39:497-501. https://doi.org/10.1007/ s00240-011-0381-y

6. Kirubarajan $A$, Buckley $R$, Khan $S$, et al. Implementing and evaluating the efficacy of an acute care urology model of care in a large community hospital. Can Urol Assoc J 2020;14:259-65. http://dx.doi.org/10.5489/cuaj.6371.

7. Guercio S, Ambu A, Mangione F, et al. Randomized prospective trial comparing immediate vs. delayed ureteroscopy for patients with ureteral calculi and normal renal function who present to the emergency department. J Endourol 2011;25:1137-41. htrps://doi.org/10.1089/end.2010.0554

Correspondence: Dr. Kamaljot S. Kaler, Department of Surgery, Section of Urology, University of Calgary, Calgary, AB, Canada; kamaljot.kaler@ucalgary.ca 